\title{
Soil Database Management Software Development for Optimizing Land Resource Information Utilization to Support National Food Security
}

\author{
Rizatus Shofiyati, Saefoel Bachri, Muhrizal Sarwani \\ Indonesian Center for Agricultural Land Resources Research and Development, \\ Indonesian Ministry of Agriculture, Bogor, Indonesia \\ E-mail: rshofiyati@litbang.deptan.go.id \\ Received April 10, 2011; revised May 13, 2011; accepted May 26, 2011
}

\begin{abstract}
Since land resource database development in 1987/1988, a large amount of digital data in spatial, tabular and metadata format has been collected and generated. There are some application softwares of soil database to manage such a large amount of data, i.e.: Side \& Horizon (SHDE4), Soil Sample Analysis (SSA), and Land Unit in dbf file, while Site and Horizon is in DataEase formats. The database contains soil physics and chemical property data of each soil horizon from surface to effective soil depth, climate, land surface conditions, and other parameters required for soil classification. Currently, database management software for land resources is still based on DOS and is stand alone. The system is not efficient and effectively used as Agricultural Land Resource Information System. At present, as a key component of this system requires review and development of new database software is compatible with the development of information technology. This paper explains about development of interactive agricultural land resources information system for optimizing land resources data utilization. Hopefully, the software can give contributions in national Agricultural Land Resources System Information development for supporting food security.
\end{abstract}

Keywords: Soil Database, Software Development, Land Resources Information, Food Security

\section{Introduction}

Indonesian soil data collection and mapping have been carried out since around 106 years ago. However, a digital soil database management (SDBM) system of Indonesian Center for Agricultural Land Resources Research and Development (ICALRD) was just started around the 80's. Since then, a large amount of digital data in spatial, tabular and metadata formats have been collected and generated [1]. The large number of soil data can be utilized to support agricultural development planning.

There are some application softwares of soil database to manage such a large amount of data, i.e.: Side \& Horizon (SHDE4), Soil Sample Analysis (SSA), and Land Unit in dbf file, while Site and Horizon is in DataEase formats. The softwares being integrated each other. Meanwhile, those soil database management software are still DOS-based and stand alone.

Soil Sample Analysis (SSA) version 2.1, an improve- ment from the previous version (1.0), is a computerized database of land specifically designed for storing, retrieval and displays the characteristics of the soil resulting from various types of methods and procedures analysis [2]. While the Site and Horizon as soil computerized database designed specifically to store and retrieve the pedon data results of the Land Resources Evaluation and Planning (LREP) I Project activities [3]. These softwares are always being improved so that in 1995 created the latest version with the name SHDE4 [4], which is a software package that linked database management system with DataEase [5]. SHDE4 is capable of storing and retrieving data group, i.e. description of the site and horizons, the reference soil series description, description of map units, monthly climate data records, data dictionary, and polygon attribute file. Further, the SSA and SHDE4 data records can be used for preparing and processing of land evaluation model on ALES (Automated Land Evaluation System), it called as SDPLE (Soil Data Preparation for Land Evaluation) [6]. The softwares have 
been designed based on geodatabase. Hence, it is relevant to GIS software platform. This database software is a tool for resource data processing and management that support the making of soil or land unit map.

The SSA and SHDE4, which are stand alone and DOS based, are still used as the main supporter of agricultural land resources information systems, especially in ICALRD. Currently, the development of a network system in which several computers work together in a system of either an intranet, internet, or LAN [7-9]. The consequences, stand-alone softwares are less supported by this system and need to be replaced by client-server and graphic user interface (GUI) based software on windows environment.

With the rapid development of information technology and community needs, the software needs to be developed to support the trend of network system, user friendly, and can be used by the wider society. Therefore, it is necessary to develop client-server application for data processing of land resources information systems. The use of compatible software that are widely used today, the soil database can be utilized more effectively and efficiently. Currently, web is an effective way to convey information that is widely available for users via internet. In future prospect, the softwares can be developed for Web-based service information systems that allow to improve the access to information in a more efficient way.

This paper explains software development of agricultural land resources information management of ICALRD to support the utilization of land resources information.

\section{Material and Methods}

\subsection{Tool Development}

Development of this application using a PC computer environment with operating system Windows XP, Windows Server 2003, Microsoft Windows 2000 Service Pack 3 or higher, with specifications of RAM 64 MB (128 MB or higher recommended) and a Pentium processor. Hard disk space 120 MB minimum required. Programming language used was Visual Foxpro Version 9.0, and is a Foxpro database (xBase format). These specifications will be the minimum needs to be able to operate the software. For now, the installation on Windows NT 4.0 Terminal Server Edition can not be done.

The main source in the development system is software applications of SHDE4 and SSA DOS, especially technical documents and user manuals. Software development has been considered a migration of operating systems with various necessary adjustments.

\subsection{Software Development}

The approach has been used for software development is the SDLC (System Development Life Cycle), based on waterfall model. This model must be done sequentially, where the next step can be done after the previous step is completed. Steps are preparation, design, implementation (verification and maintenance), and socialization. Steps of procedure are presented in Figure 1.

\section{Results and Discussion}

\subsection{Soil Database Software Migration}

The Powerful computer programs can help manage and accelerate the process of providing data accurately. The computer applications that have been developed are not enough to handle the needs of current data management. Migration of those tailored software (those we already made) for land resource database management needs to be done to optimize the utilization of land resources data.

Migration of SSA and SHDE4 (DOS Version) to Windows-based software required in order to facilitate processing and data management systems and its compatibility to the current trend. Software migration has been made with reference to existing tables, which have been built on the system of naming and defining fields/ variables. Some adjustments have been made for compatibility to other related systems. The software migration has considered some aspects, such as: availability and continuity of programs, reliability program and database system, the ease of writing and programming, compatibility database format to the other.

The differences of SSA and SHDE4 software migration which is operated under Windows and the previous software under DOS explained in Table 1.

\subsection{Soil Database Management System}

Relationship of SH and SSA softwares with other application software described in Figure 2. Data flow diagram in Figure 2 describes a series of processes, data and related parties (external agent) that took place in the system. Descriptions of soil profile have been collected and recorded in special form during soil survey. Soil sample was taken from the field will be analyzed in laboratories to complete data for land resources information. The SH and SSA data are inputted, stored, processed, and updated in SH and SSA softwares [10].

SH and SSA can be integrated with other existing systems, include GIS (Geographic Information System) and SDPLE (Site Data Processing for Land Evaluation). The SH and SSA data can be extracted for cartographic map- 


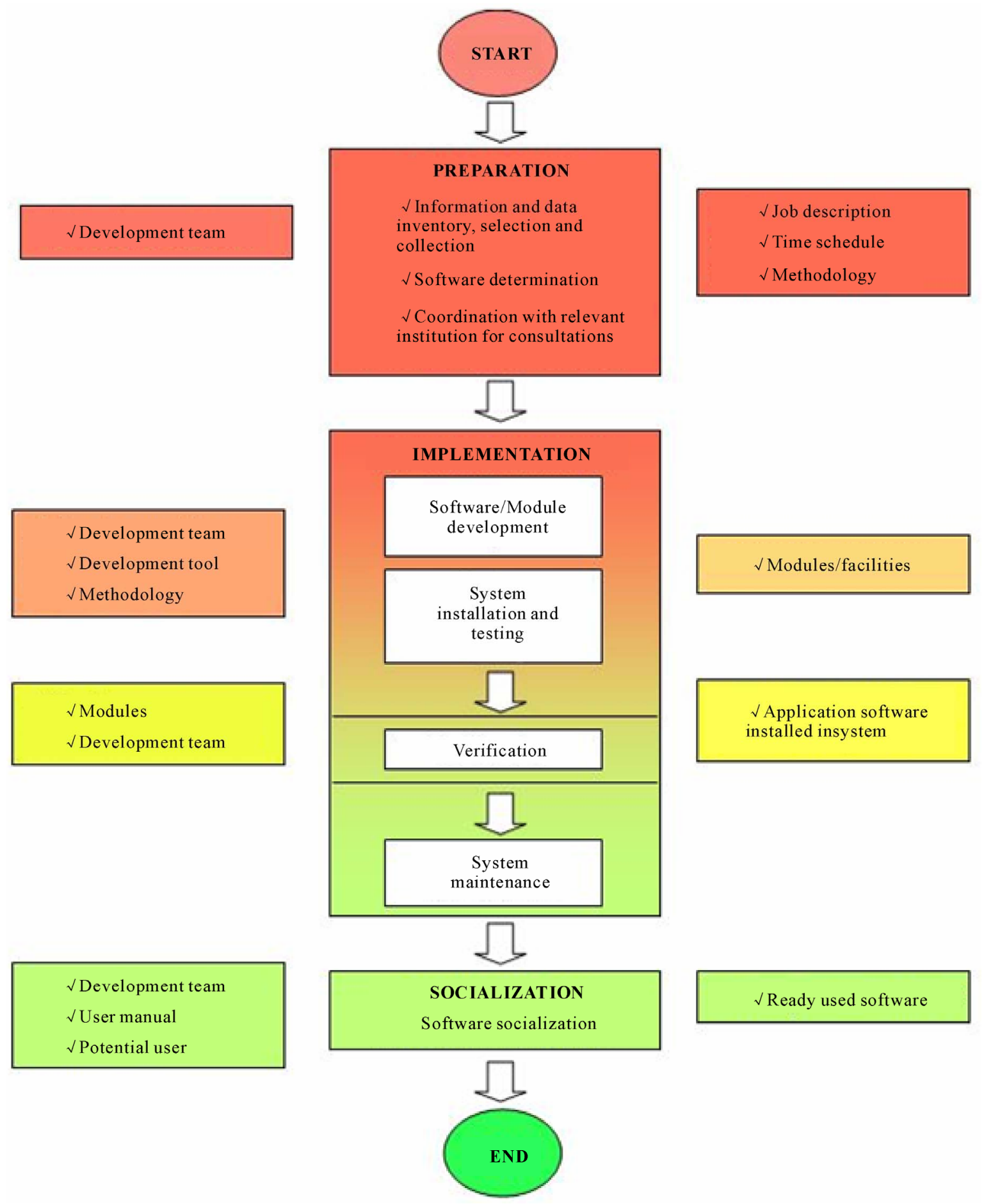

Figure 1. Steps of soil database software development.

ping purposes in GIS. The items selected can also be used for land evaluation, or calculation of soil carbon, soil nutrient status, and others. The SH and SSA are data source for processing in these systems.

In this case, extracted representative data have been used to improve land units information. Representative of data (observation) used as input for SDPLE associated with ALES (as land evaluation application) in the modeling process in order to obtain land suitability classes. Furthermore, the evaluation class can be processed to get information for the use of agricultural land recommendations. The information can be used for government to 
Table 1. Comparison of DOS versus Windows versions of SSA and SHDE4 data.

\begin{tabular}{|c|c|c|c|}
\hline No & Description & SSA \& SHDE4 (DOS Version) & SSAFOX \& SHFOX (Windows Version) \\
\hline 1. & User interface & $\begin{array}{l}\text { Text-based and command-line operating system; not } \\
\text { fully compatible with GUI operating system (Win- } \\
\text { dows) and relatively not effective. }\end{array}$ & $\begin{array}{l}\text { Windows display is easier in operation, graphi- } \\
\text { cal operating mode, so that it looks more attrac- } \\
\text { tive, and compatible on almost all types of ap- } \\
\text { plication programs. }\end{array}$ \\
\hline 2. & Compatibility & $\begin{array}{l}\text { Need longer steps for data conversion to another } \\
\text { format }\end{array}$ & $\begin{array}{l}\text { Compatible with other formats, making it more } \\
\text { practical and quick }\end{array}$ \\
\hline 3. & Network system & $\begin{array}{l}\text { Stand alone; difficult to support trend of networked } \\
\text { systems }\end{array}$ & Compatible to network systems \\
\hline 4. & Processing & $\begin{array}{l}\text { Take longer for processing; the list option is dis- } \\
\text { played in the page side, not entry data field box, } \\
\text { need }>1 \text { page for each theme of data entry displays }\end{array}$ & $\begin{array}{l}\text { Faster and easier, list of field selection directly } \\
\text { displayed on entry data field box, theme can be } \\
\text { displays in } 1 \text { page. }\end{array}$ \\
\hline 5. & Development & Out of date & Easier and up to date \\
\hline 6. & Management & $\begin{array}{l}\text { Complicated \& difficult to store large amounts of } \\
\text { data (max } 10,000 \text { records) }\end{array}$ & $\begin{array}{l}\text { More effective \& efficient, can store large } \\
\text { amounts of data ( }>10,000 \text { records) }\end{array}$ \\
\hline
\end{tabular}

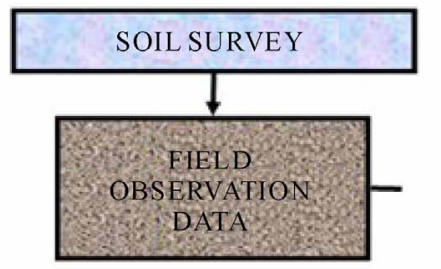

Field data input

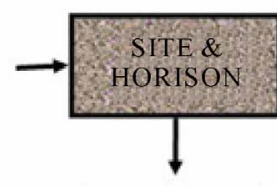

Determining data

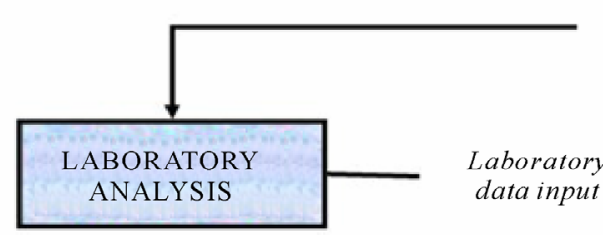
representative

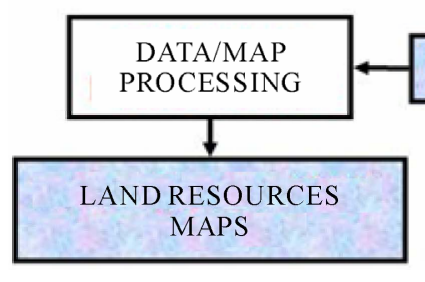

Figure 2. Flow diagram of land resources data of ICALRD.

support agricultural development in agriculture planning and recommendation, especially national food security and safety.

\subsection{Practical Implication}

SSAFOX and SHFOX system can be used in a variety of stakeholders engaged in agricultural land resources, specifically for the purpose of inventory and management control of research and land mapping data. Application programs can be used in field and post field work. Utilization of the program during the last observation allows researchers and surveyors to perform data correlation and correction. While the use of post field survey or research, 
in addition to entry, updating, also can be done to synchronize the data on the results of laboratory data.

The system maintenance is suitable sustainable to monitor of error during their use, adding features and application development in accordance with user needs and development of information technology. SSAFOX and SHFOX application Version 1.0 have been designed to serve the various needs of land resource data management based on results of soil mapping. The features available on the program include: data entry, editing, and preparing reports in the form of a description of the profile and other reports. Special procedures of land evaluation data preparation are also provided to allow users to do land evaluation.

\subsection{Soil Database Utilization for Food Security}

Food security model can be built by using soil database. It is also required other inputs, such as legal aspect, socio economic, and institutional. An enormous leap in technologies that allows for accurate collection and prediction of soil properties is needed for pressing issues such as food security. The end user, such as modeling communities, farmers, land users, and policy and decision makers need accurate, up-to-date and spatially referenced soil information. This need coincides with major advances in technologies for the prediction of soil properties. Soil data utilization to support national food security is shown in Figure 3.

SSAFOX and SHFOX were designed for persons or institution who involved in land mapping and land evaluation, and considered for other purposes. Each institution can use it in accordance with available data. The software can accommodate large amounts of data so that in this way has contributed to the development of na- tional land resources system information. The need of spatial information software can be fulfilled in the soil of this database system. Its ability to connect automatically with GIS software can optimize utilization of soil data collected for modeling of agricultural Land Resources. Recommendations can be obtained by combining with the legal aspects, socio-economic and institutional aspect.

\section{Conclusions}

- Land resources data is very important to support agricultural development. The data can be used both for technological innovation development and land capability assessment aspects.

- Management of land resource database needs to be optimized its utilization by developing a software xBase-formatted database system that has high compatibility with other database systems, as well as having data storage capabilities in a very large size and easy to manage. In addition, the software for SDBMS must be able and easily to be developed by connecting with other application softwares to meet the development needs of the application of land resources.

- By using software that has been developed its capabilities and can be operated in environments with Windows operating system, use of land resources database can be optimized utilization to support food security.

\section{Acknowledgements}

The authors are grateful to the ICALRD for providing facilities, data and encouragement for this study. Authors

$$
\text { Data Input Data Processing Output Management Recommendation }
$$

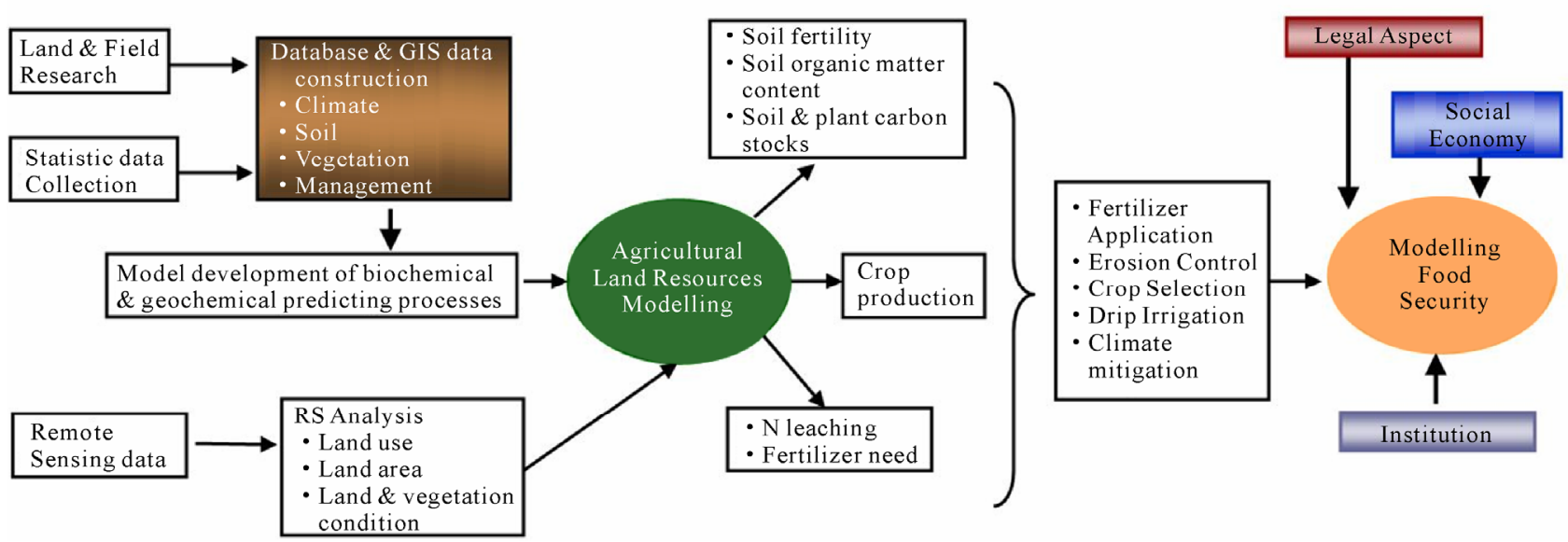

Figure 3. The utilization of soil database for supporting food security. 
are also thankful to State Ministry for Research and Technology for providing funds for this research activity.

\section{References}

[1] R. Shofiyati, I. Las and F. Agus, "Indonesian Soil Data Base and Predicted Stock of Soil Carbon,” In: Z. S. Chen and F. Agus, Eds., Proceedings of International Workshop on Valuation and Sustainable Management of Soil Carbon Sequestration in Asian Countries, Bogor, 28-29 September, 2010, Indonesian Soil Research Institute, ICALRRD, IAARD, Ministry of Agriculture, Indonesia, Food \& Fertilizer Technology Center of Taiwan, and National Institute for Agro-Environmental Sciences of Japan for the Asian and Pacific Region, 2010.

[2] A. Muslihat, U. Wood-Sichra, P. Buurman and M. G. Wijayanto, "Soil Sample Analysis Data Base," User Manual and Technical Manual, Technical Report No. 17 Ver 2.1., LREPP Part 2. Soil Database Management, CSAR, Bogor, 1990.

[3] U. Wood-Sichra, "Computer Coding Forms and Computerized Data Entry for Field Data (DATAEASE)," Technical Report, No. 6, Ver 2.0, LREPP Part 2, Soil Database Management, CSAR, Bogor, 1990.

[4] U. Wood-Sichra, "SHDE4 Ver. 3.0: A Site and Horizons Data Base using DataEase 4.2,” Operations and Technical
Manual, LREPP-II Part C, Technical Report No. 12, Version 3.0., CSAR, Bogor, 1995.

[5] DataEase International Inc., DataEase Ver. 4.0, Rel. 2, Volume 1, Reference Manual Users Guide, Volume 2 DB, Administration and Development Guide, Volume 3 DQL, Guide Reference Manual, USA, 1988.

[6] E. van der Zee, "Soil Data Processing for Land Evaluation,” Technical Report, No. 19, Version 1.0., 1996.

[7] S. Vaughan-Nichols, R. Tidrow, L. Buhle, J. Kuffer dan N. Taylor, "All you Need to Know about the World Wide Web (Yang perlu Anda ketahui tentang World Wide Web),” I. Putrajaya (Translator). ANDI, Yogyakarta. 1999.

[8] C. Xavier, "World Wide Web Design with HTML," McGrawa-Hill, Boston, 2000.

[9] E. Turban, J. E. Aronson and T.-P. Liang, "Decision Support System and Intelligent System,” ANDI, Yogyakarta. 2005.

[10] R. Shofiyati, "Development of Land Resources Information System and Web-Based Fertilizer Technology Able to Improve Technical Efficiency Index $>15 \%$. Pengembangan Sistem Informasi Sumberdaya Lahan dan Teknologi Pupuk Berbasis Web yang Mampu Meningkatkan IET > 15\%," Final Report of Applied Research Program Incentives, Indonesian Center for Agricultural Land Resources Research and Development, Bogor, 2010. 